\title{
Botulinum toxin in writer's cramp: objective response evaluation in 31 patients
}

\author{
J Wissel, C Kabus, R Wenzel, S Klepsch, U Schwarz, A Nebe, L Schelosky, U Scholz, \\ W Poewe
}

\begin{abstract}
Objectives-To quantify the treatment effect of local botulinum toxin injections in writer's cramp a newly developed rating scale of writing performance and a computer assisted analysis of writing speed were used in 31 patients undergoing botulinum toxin therapy.

Methods-Baseline data of the writer's cramp rating scale (WCRS, see appendix) and computer based writing speed analysis were compared with those obtained at the time of subjective best response as recorded during follow up visits.

Results-The mean dose injected per session was 133.2 units Dysport ${ }^{\circ}$ divided between two forearm muscles. Of all 124 injection sessions during mean follow up of one year $76 \%$ produced a good improvement. The most common side effect was weakness $(72 \%$ of the follow up visits). The WCRS scores as assessed by a blinded videotape review by four independent raters showed good reliability between raters and a significant improvement after treatment $(P<0.001)$. The speed of pen movements showed a significant $(P<0.05)$ increase after treatment at subjective best effect recordings and a significant correlation with WCRS subscores, documenting the validity of the scale.

Conclusion-The present study is the first to show significant effects of botulinum toxin treatment in patients with writer's cramp on the basis of a quantifiable scale for writing performance which correlates significantly with writing speed measurements. The WCRS as employed in this study might therefore prove a useful rating instrument in other studies assessing severity and treatment response in patients with writer's cramp.
\end{abstract}

$(\mathcal{F}$ Neurol Neurosurg Psychiatry 1996;61:172-175)

Keywords: writer's cramp; botulinum toxin; writer's cramp rating scale

Writer's cramp is one of the three most frequent types of idiopathic adult onset focal dystonia. Several open label ${ }^{1-6}$ and three double blind studies ${ }^{7-9}$ have shown the efficacy of botulinum toxin treatment in this condition. However, most of the published reports lack objective or quantifiable response variables. Only two recent studies ${ }^{8} 9$ have tried to overcome this, by using stop watch assessments of writing speed and pen control measurements during standard tasks. Although these two studies found improvements in writing speed and pen control, many neurologists still regard botulinum toxin treatment of writer's cramp less rewarding than treatment of craniocervical dystonias.

This study was performed to assess the effects of botulinum toxin treatment on writing performance by objective and quantifiable variables with a newly developed standardised rating scale (writer's cramp rating scale (WCRS)) and a computer based writing speed analysis.

\section{Patients}

Thirty one patients (16 women and 15 men) with writer's cramp were studied after we obtained informed consent and approval by the local ethics committee. Their mean age at onset was $34 \cdot 8$ (range 20-73) years and the mean duration of symptoms was $12 \cdot 3$ (range $0 \cdot 6-35$ ) years. Thirty patients were right handed, one left handed. All patients experienced symptoms within a few seconds of picking up a pen. Pain or uncomfortable tension in the affected limb was present in 20 patients. Twenty nine were professionally active, mostly as office employees, but $80 \%$ were substantially handicapped by their writing disability. Superimposed on dystonic posturing nine patients showed a mild intermittent writing tremor and in three patients writing tremor was the dominant complaint. According to Sheehy and Marsden ${ }^{10} 15$ patients were classified as having simple writer's cramp, 16 as having dystonic writer's cramp, and according to Cohen et $\mathrm{al}^{1}$ four as having localised, 27 as having non-localised writer's cramp. Four patients $(12.9 \%)$ each had additional dystonic features (segmental dystonia in three and multifocal dystonia in one) or postural hand tremor. All but seven had received various treatments including pharmacological and behavioural therapy without any substantial consistent benefit.

Thirty healthy subjects (17 women and 13 men, mean age $40 \cdot 2$ (26-65) years) served as controls for computer based writing speed analysis.

\section{Methods}

ASSESSMENTS

For objective clinical assessments a newly developed scale-the writer's cramp rating scale (WCRS, see appendix) was employed at baseline and follow up visits. To ensure standardised procedures subjects were always 
seated in the same position, 3-4 metres in front of a rater and were asked to write the same four lines of 10 interconnected "l" letters plus a standard text of four lines, using the same pen at all sessions. For subsequent blinded ratings standardised video recordings were made during the writing task.

For objective analysis of writing speed the movement of the tip of a special pen was recorded by a digitising tablet connected to a 386 computer (sampling frequency $166 \mathrm{~Hz}$, accuracy $0.25 \mathrm{~mm}$ ) at every follow up visit. Using a commercially available software package for writing movement analysis writing speed was assessed as frequency of 10 interconnected "l" letters."

Treatment effects after local botulinum toxin injections were graded subjectively by the patients on a continuous scale $(0 \%=$ no change, $100 \%$ normal undisturbed writing).

The extent of maximal weakness for a given injection session was scored by the patient on a scale 0 to $2(0=$ no, $1=$ mild, and $2=$ functionally important weakness) and assessed at follow up visits with the Medical Research Council (MRC) scale.

\section{INJECTIONS AND FOLLOW UP}

Muscle selection for injections was based on clinical criteria of postural deviations of the hand and fingers and responsible muscle forces in 27 patients. Two patients presented predominant writing tremor and injections were placed into those muscles showing prominent tremor bursts during surface EMG of forearm flexors and extensors when writing (one patient flexors only, one patient alternating flexors and extensors). Two complained of writing blocks without clinically evident dystonic posturing and injections were targeted into cocontracting antagonists as seen on the EMG polygram. ${ }^{12}{ }^{13}$ All injections were performed under EMG guidance using a monopolar Teflon coated needle. The initial dose of botulinum toxin was 60 units Dysport for finger movers and 80 units Dysport for wrist movers. Patients were evaluated at two to four week intervals after each injection. If there was less than $20 \%$ subjective improvement and no weakness at follow up a repeat injection was performed. For repeat injections doses were modified and, if necessary, injected muscles were changed to achieve the best possible subjective response with minimal side effects (paresis). The interval between successive injections ranged between two weeks and eight months.

\section{TREATMENT EVALUATION}

The following assessments were made at each follow up visit:

- Magnitude of subjective response on scale from $0 \%$ to $100 \%$ (three subjective response groups were defined as follows: less than $20 \%=$ no, 20 to less than $60 \%=$ moderate, and 60 to $100 \%=$ marked improvement)

- Latency and duration of relief of symptoms and side effects

- Speed of writing (computer based),

- Video recordings of the patients when per- forming the standardised writing task.

For objective assessment of efficacy the WCRS was applied to video recordings at the times of baseline before the first ever injection and at the time of best subjective response at one of the follow up visits by four neurologists experienced in movement disorders but not involved in this study. Standardised video recordings of the standardised writing task (see methods) of patients before and after treatment as well as controls were presented to the observers in random sequence. The raters were unaware of patient, control, or treatment status and care was taken that no elements of the video recording were likely to make identification of patients, controls, or treatment status possible.

\section{STATISTICAL ANALYSIS}

Statistical analysis was performed with the Wilcoxon and Kruscal-Wallis tests. Correlations between WCRS and writing speed were calculated by Spearman's rank correlation coefficient. The interrater reliability of the WCRS was calculated for every item using Cohen's $\kappa$ coefficient.

\section{Results}

INJECTION DATA

Patients have now been followed up for a mean of 11.8 (range 2-29) months during which time there was a mean number of four (range 1-10) injection sessions yielding a total of 124 sessions. The mean dose injected per session was 133.2 (range 40-240) units Dysport divided between two muscles on average (mean 1.95 (range 1-4) muscles per session) yielding a mean cumulative total dose of 542.4 (range 140-1640) units Dysport per patient.

Out of the 14 treated forearm muscles the most commonly injected muscles were the flexor carpi ulnaris $(n=57)$ and radialis $(n=$ 30 ), flexor digitorum superficialis digitorum II and III $(n=49)$, flexor pollicis longus $(n=$ $28)$, and the extensor carpi ulnaris $(n=32)$.

SUBJECTIVE RESPONSE AND SIDE EFFECTS

Of all 124 treatment sessions $76 \%$ produced significant subjective improvement of greater than $20 \%$. When analysing the best ever recorded subjective response over the entire follow up period $25(80.6 \%)$ of 31 patients experienced a greater than $20 \%$ improvement ( 18 patients $20 \%-<60 \%$ and seven patients $60 \%-100 \%$ improvement) with a mean response latency of 7.6 (range 1-15) days, a mean latency of 20.8 (range 10-38) days to best ever recorded subjective response and mean duration of improvement of 59.6 (range 6-195) days. Five patients discontinued botulinum toxin treatment because of lack of improvement after three successive injections.

Weakness of injected muscles was the most prevalent side effect, affecting 27 of 31 patients at least once over the entire follow up. It was functionally relevant in only three instances (grade 3 on the MRC scale), whereas in most (81 visits) it was functionally irrelevant (grade 4 on the MRC scale). 
BLIND VIDEO RATING OF WCRS

The mean subscore for part A (dystonic posture, latency of dystonia, and writing tremor) at baseline was $9 \cdot 1$ (SD 4.5). There was a significant $(P<0.001)$ decrease after treatment with a mean subscore value for the entire group of 6.6 (SD $4 \cdot 1$ ) at the time of best videotaped subjective effect. The subscore part B (writing speed) was also significantly $(P<0.05)$ decreased compared with baseline (baseline 1.1 (SD 0.5); post-treatment 0.8 (SD $0 \cdot 6)$ ).

When patients were divided into subjective response subgroups (see above) significant changes in the WCRS subscore part A from baseline to post-treatment values were only reached in the subgroups with moderate $(\mathrm{n}=$ 18; baseline $9 \cdot 2$ (SD 4.3); post-treatment 8.0 (SD 3.6); $\mathrm{P}<0.01)$ and marked $(\mathrm{n}=7$; baseline 9.3 (SD 3.8); post-treatment 3.8 (SD 4.2); $\mathrm{P}<0.05$ ) improvement.

\section{INTERRATER RELIABILITY OF THE WCRS}

Interrater reliability assessments for the four blinded raters yielded $\kappa$ coefficients of $0.4-0.85$ documenting moderate $(0.4-0.6)$ or substantial $(>0.6)$ interrater agreement, for all but the items for elbow extension $(0 \cdot 25-0.39)$ and finger I and II extension (0.23-0.55).

\section{COMPUTER BASED WRITING SPEED ANALYSIS}

The speed of pen movements for 10 interconnected " 1 " letters showed only little differences between two recordings in controls but a significant increase $(P<0.05)$ in patients after treatment at the time of best recorded subjective response. The table shows the mean baseline and post-treatment frequencies of all patients, the three subjective response subgroups, and controls (examinations 1 and 2). Significant $(P<0.05)$ changes from baseline to peak response were only reached in the moderate subjective response group. Patients of the other two subjective response groups also showed increased writing speed after treatment but the relative change from their baseline values was not significant, the latter being close to controls in the patients with a marked subjective response.

A significant correlation was found between the computer based analysis of writing speed measured as frequency of interconnected "l" letters and the WCRS subscores part A (dystonic posture, latency of dystonia, and writing tremor; $P<0.05$ ) and part $B$ (writing speed; $P<0.01)$.

Writing speed analysis: mean frequency of interconnected " $l$ " letters at baseline and best subjective effect at follow up in 31 patients with writer's cramp and at two examinations in 30 healthy controls

\begin{tabular}{|c|c|c|}
\hline $\begin{array}{l}\text { Patients and } \\
\text { controls }\end{array}$ & $\begin{array}{l}\text { Baseline } \\
\text { mean frequency } \\
(\mathrm{Hz})\end{array}$ & $\begin{array}{l}\text { Post-treatment } \\
\text { mean frequency } \\
(\mathrm{Hz})\end{array}$ \\
\hline $\begin{array}{l}\text { All patients }(n=31) \\
\text { Patients with no improvement }(n=6) \\
\text { Patients with moderate improvement }(n=18) \\
\text { Patients with marked improvement }(n=7) \\
\text { Controls }(n=30)\end{array}$ & $\begin{array}{l}1.6(\text { SD } 0.74) \\
0.88(\text { SD } 0.30) \\
1.66(\text { SD } 0.67) \\
2.07 \text { (SD } 0.76) \\
2 \cdot 82(\text { SD } 0.85) \\
\text { (examination } 1)\end{array}$ & $\begin{array}{l}\left.1.96^{\star} \text { (SD } 0.84\right) \\
1.27 \text { (SD } 0.38) \\
\left.1.97^{\star} \text { (SD } 0.66\right) \\
2.53 \text { (SD } 1.17 \text { ) } \\
2.78 \text { (SD } 0.73 \text { ) } \\
\text { (examination } 2 \text { ) }\end{array}$ \\
\hline
\end{tabular}

Patients were subdivided in response groups (no, moderate, and marked improvement). $\star \mathrm{P}<0.05$.

\section{Discussion}

The present results confirm that patients with writer's cramp can benefit from repeated local injections of botulinum toxin. As in previous series $^{1-6}$ about $80 \%$ of patients reported subjective improvement which lasted for about 60 days on average.

In the present series computer based analysis not only showed significant increases in writing speed after injections but also seemed to be of potential value in predicting subjective outcome: those patients in this series with baseline frequencies of writing interconnected "l" letters of greater than $2 \mathrm{~Hz}$ had the best subjective response to subsequent botulinum toxin injections whereas writing speed with frequencies below $1 \mathrm{~Hz}$ seemed to be associated with poor subjective outcome. There was no significant improvement in writing speed in those patients with a pronounced subjective response. This can be explained both by the few subjects in this subgroup as well as by the baseline values of writing speed, which were the least different from normal making the treatment induced increase numerically small. Both factors influence significance. Further studies are needed to assess whether kinematic variables other than writing speed would provide variables of even closer correlation with clinical outcome or predictive value.

As well as recording subjective response and measuring writing speed, a newly developed scale was used to score the severity of different clinical components of writer's cramp and to evaluate treatment effects. The WCRS is easy to use, can be completed in about 10 minutes with minimal instructions, and shows sufficient interrater reliability. There were significant decreases for total scores and subscores for dystonic posture, writing tremor, and writing speed after treatment and these changes correlated with objective measurements of writing speed, documenting the validity of the scale.

The WCRS as employed in this study might therefore prove a useful rating instrument in other studies assessing severity and treatment response in patients with writer's cramp.

Whereas other studies reported special benefit in subgroups of patients we found no statistical significant difference in response and side effect profile between young ( $<50$ years) and old or female and male patients or between clinical subtypes (simple or dystonic, localised or non-localised, primarily flexor or extensor spasms) of writer's cramp.

The present study is the first to demonstrate significant effects of botulinum toxin treatment in patients with writer's cramp on the basis of a quantifiable scale for writing performance which correlates significantly with writing speed measurements.

Further use of computer based writing analysis is encouraged to test its potential to provide predictive outcome measures and select patients for botulinum toxin treatment. This work was supported by BMBF Nr 01KL9201/8. We thank
A Mohnhaupt, Berlin, for assistance in statistical analysis. The study was presented in part at the third movement disorder constudy was presented in part at the third mover
gress in Orlando, Florida, November 1994. 


\section{Appendix}

Writer's Cramp Rating Scale

Part A: writing movement score

\begin{tabular}{|c|c|c|c|}
\hline \multicolumn{2}{|l|}{$\begin{array}{l}\text { 1. dystonic posture* } \\
\text { elbow score (ES) }\end{array}$} & & \\
\hline 0 & no & 0 & 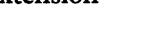 \\
\hline 1 & moderate & 1 & \\
\hline 2 & marked & 2 & E S $(0-2)$ \\
\hline \multicolumn{4}{|l|}{ wrist score (WRS) } \\
\hline pathological flexion & \multicolumn{3}{|c|}{ pathological extension } \\
\hline 0 & no & 0 & \\
\hline 1 & moderate & 1 & \\
\hline 2 & marked & 2 & \\
\hline \multicolumn{4}{|c|}{ pathological ulnar-abd. pathological radial-abd. } \\
\hline 0 & no & 0 & \\
\hline 1 & moderate & 1 & \\
\hline 2 & marked & 2 & WRS $(0-4)$ \\
\hline \multirow{2}{*}{\multicolumn{4}{|c|}{$\begin{array}{l}\text { finger score (FS) } \\
\text { finger I }\end{array}$}} \\
\hline $\begin{array}{l}\text { finger I } \\
\text { pathological flexion }\end{array}$ & \multicolumn{2}{|c|}{ pathological extension } & \\
\hline 0 & no & 0 & 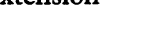 \\
\hline 1 & moderate & 1 & \\
\hline 2 & marked & 2 & \\
\hline \multicolumn{4}{|l|}{ finger II } \\
\hline 0 & no & 0 & \\
\hline 1 & moderate & 1 & \\
\hline 2 & marked & 2 & \\
\hline \multicolumn{4}{|c|}{ finger III } \\
\hline 0 & no & 0 & \\
\hline 1 & moderate & 1 & \\
\hline 2 & marked & 2 & F S $(0-6)$ \\
\hline $\begin{array}{l}\text { 2. Latency of dystonia } \\
\text { at least } 3 \text { letters pos }\end{array}$ & $\begin{array}{l}L \text { ) } \\
\text { sible }\end{array}$ & 1 & \\
\hline \multirow{2}{*}{\multicolumn{4}{|c|}{ 3. Writing tremor (WT) }} \\
\hline & & & \\
\hline $\begin{array}{l}\text { no wrung remor } \\
\text { moderate writing }\end{array}$ & mor & 1 & \\
\hline severe writing trem & & 2 & W T $(0-2)_{-}$ \\
\hline
\end{tabular}
writing speed (WS)

\section{Part B: Writing speed}

$\begin{array}{lll}\text { normal } & 0 & \\ \text { mild slowing } & 1 & \\ \text { severe slowing } & 2 & \text { W S }(0-2)\end{array}$

The WCRS consists of two subscores, the writing movement score and the writing speed subscore:

$$
\begin{array}{lr}
\text { Writing movement score }=(\mathrm{ES}+\mathrm{WRS}+\mathrm{FS}) \times \mathrm{L}+ \\
\text { WTS } \times 2 & (0-28) \\
\text { Writing speed score }=\text { WS } & (0-2)
\end{array}
$$

*Following a study in 24 healthy controls a "normal writing posture" of the upper extremity was defined as an elbow flexion of around 90 degrees, a neutral position of the wrist concerning extension, flexion and ulnar- or radialabduction of the wrist and a flexion of around 25 degrees in the finger joints of the first, second and third finger. To ensure standardised procedures subjects should keep the same sitting position and distance to the table while writing a standard text with always the same pen during each assessment.

1 Cohen GC, Hallett M, Geller BD, Hochberg F. Treatment of focal dystonias of the hand with botulinum toxin injections. F Neurol Neurosurg Psychiatry 1989;52:355-63.

2 Jancovic J, Schwartz K, Donovan DT. Botulinum toxin treatment of cranial-cervical dystonia, spasmodic dysphonia, other focal dystonias and hemifacial spasm. F Neurol Neurosurg Psychiatry 1990;53:633-9.

3 Rivest J, Lees AJ, Marsden CD. Writer's cramp: treatment with botulinum toxin injections. Mov Disord 1991;6:55-9.

4 Poungvarin N. writer's cramp: the experience with botulinum toxin injections in 25 patients. 7 Med Assoc Thai 1991;74:239-47.

5 Lees AJ, Turjanski N, Rivest J, Whurr R, Lorch M, Brookes G. Treatment of cervical dystonia, hand spasms and laryngeal dystonia with botulinum toxin. F Neurol 1993;239: geal

6 Karp BI, Cole RA, Cohen LG, Grill S, Lou JS, Hallett M. Long-term botulinum toxin treatment of focal hand dystoLong-term botulinum toxin

7 Yoshimura DM, Aminoff MJ, Olney RK. Botulinum toxin therapy for limb dystonias. Neurology 1992;42:627-30.

8 Tsui JKC, Bhatt M, Calne S, Calne DB. Botulinum toxin in the treatment of writer's cramp: a double-blind study. Neurology 1993;43:183-5.

9 Cole R, Hallett M, Cohen LG. Double-blind trial of botulinum toxin for treatment of focal hand dystonia. Mov Disord 1995;4:466-71.

10 Sheehy MP, Marsden CD. Writer's cramp-a focal dystonia. Brain 1982;105:461-80.

11 Marquardt C, Mai N. A computational procedure for movement analysis in handwriting. F Neurosci Methods 1994; 52:39-45.

12 Wissel J, Belian R, Kleppek B, Schelosky L, Ebersbach G, Kabus C, Poewe W. Clinical features and surface electromyoraphic patterns in 20 patients with writer's cramp tromyographic patterns in 20 patients with writer's cramp

13 Kleppek B, Wissel J, Kabus C, Schelosky L, Poewe W. Veränderungen in der Oberflächenelektromyographie von Ober- und Unterarmmuskeln bei 24 Patienten mit Graphospasmus. In: Huffmann G, Braune H-J, Henn KGraphospasmus. In: Huffmann G, Braune H-J, Henn KGermany: Einhorn-Presse, 1994:385-9.

14 Landis JR, Koch GG. The measurement of observer agreement for categorical data. Biometrics 1977;3:159-73. 